\title{
Dietary L-arginine supplementation reduces Methotrexate-induced intestinal mucosal injury in rat
}

\author{
Tal Koppelmann ${ }^{1,3}$, Yulia Pollak ${ }^{1}$, Jorge Mogilner ${ }^{2}$, Jacob Bejar ${ }^{4}$, Arnold G Coran ${ }^{5}$ and Igor Sukhotnik ${ }^{1,2^{*}}$
}

\begin{abstract}
Background: Arginine (ARG) and nitric oxide maintain the mucosal integrity of the intestine in various intestinal disorders. In the present study, we evaluated the effects of oral ARG supplementation on intestinal structural changes, enterocyte proliferation and apoptosis following methotrexate (MTX)-induced intestinal damage in a rat.

Methods: Male rats were divided into four experimental groups: Control rats, CONTR-ARG rats, were treated with oral ARG given in drinking water 72 hours before and 72 hours following vehicle injection, MTX rats were treated with a single dose of methotrexate, and MTX-ARG rats were treated with oral ARG following injection of MTX. Intestinal mucosal damage, mucosal structural changes, enterocyte proliferation and enterocyte apoptosis were determined 72 hours following MTX injection. RT-PCR was used to determine bax and bcl-2 mRNA expression.
\end{abstract}

Results: MTX-ARG rats demonstrated greater jejunal and ileal bowel weight, greater ileal mucosal weight, greater ileal mucosal DNA and protein levels, greater villus height in jejunum and ileum and crypt depth in ileum, compared to MTX animals. A significant decrease in enterocyte apoptosis in the ileum of MTX-ARG rats (vs MTX) was accompanied by decreased bax mRNA and protein expression and increased bcl-2 protein levels.

Conclusions: Treatment with oral ARG prevents mucosal injury and improves intestinal recovery following MTXinjury in the rat.

Keywords: Methotrexate, Mucositis, Intestine, Arginine, Rat

\section{Background}

Mucositis is a debilitating, dose-limiting, and costly side effect of cancer therapy. Mucositis occurs in $40 \%$ of cancer patients after standard doses of treatment and in almost $100 \%$ of patients treated with high doses of chemotherapy [1] and can affect the entire gastrointestinal tract causing discomfort, nausea, vomiting, bloating, diarrhoea, ulceration, bleeding and in some cases result in septicaemia [2]. The mechanisms of mucositis are poorly understood. It has been suggested that proinflammatory cytokines, e.g., TNF- $\alpha$ and IL-1 $\beta$, may be involved in the amplification phase of intestinal mucositis [3].

Arginine is a non-essential amino acid processed metabolically by the urea cycle and involved in multiple

\footnotetext{
* Correspondence: igor-dr@internet-zahav.net

'The Bruce Rappaport Faculty of Medicine, Technion-Israel Institute of Technology, Laboratory of intestinal adaptation and recovery, Haifa, Israel Full list of author information is available at the end of the article
}

metabolic and biologic processes including release of several hormones, immune response, the regulation of inflammation, collagen synthesis during wound healing, and tumor biology [4]. L-Arginine is the precursor for the formation of nitric oxide (NO), an important signaling molecule involved in neurotransmission, vascular homeostasis, immune regulation, and host defense [5]. In addition, arginine is an essential metabolic substrate for immune cells and required for normal lymphocyte function [6]. Arginine and NO are critical to the normal physiology of the gastrointestinal tract. Several studies have suggested that endogenous formation of nitric oxide maintains the mucosal integrity of the intestine and protects the gut from injuries from blood-borne toxins and tissue destructive mediators $[7,8]$. In a recent study, we have shown that oral arginine decreases intestinal injury caused by lipopolysacharide endotoxemia in a rat [9]. In another study, we have demonstrated

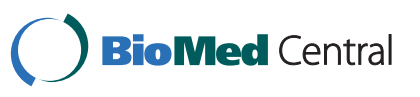


that oral arginine administration improves mucosal recovery following intestinal ischemia/reperfusion injury in the rat [10]. In a recent review, Drover et al. have described that perioperative administration of arginine supplemented diets in elective surgical patients results in a substantial reduction in infectious complications and shorter hospital length of stay, with no overall effect on mortality compared with standard care [11].

The purpose of this study was to evaluate the effectiveness of dietary L-arginine in prevention of methotrexate (MTX) induced intestinal damage in a rat model and to investigate the mechanisms involved in the stimulating effect of arginine on enterocyte turnover including its effects on cell proliferation and cell death via apoptosis.

\section{Methods}

\section{Animals}

The experimental protocol was approved by the "Guide for the Care and Use of Laboratory Animals," Rappaport Faculty of Medicine, Technion (Haifa, Israel). Male Sprague-Dawley rats weighing 250-300 g were acclimatized at $21^{\circ} \mathrm{C}$ on 12 -h day and night cycles for a minimum of 1 week before experimentation. The rats had free access to water and were pair-fed with standard chow.

\section{Experimental design}

Animals were randomly assigned to one of four experimental groups of 8 rats each: (1) sham rats (Group A), (2) sham-ARG rats were pretreated with ARG given in drinking water (2\%) for 7 days (Group B), (3) MTX rats, which underwent methotrexate injury by a single intraperitoneal injection of $20 \mu \mathrm{g} / \mathrm{kg}$ and were sacrificed 3 days later (Group C), and (4) MTX-ARG animals, which were pretreated with ARG given in drinking water 3 days before and 3 days after MTX injection (Group D).

\section{Intestinal morphology analysis}

The small intestine was removed and divided into two segments: proximal jejunum (10 from the Treitz ligament) and terminal ileum $(10 \mathrm{~cm}$ from ileo-cecal junction). Each segment was weighed, mucosa was scraped off, weighed and snap frozen in liquid nitrogen. Mucosal samples (100 mg) were homogenized using Kontes Tenbroeck Tissue Grinder. DNA and protein were extracted using TRIZOL reagent as described by Chomczynski [12]. The DNA concentrations were recorded spectrophotometrically and calculated per $\mathrm{cm}$ of bowel length. Final protein concentration was measured spectrophotometrically using a commercially available kit (Bio-Rad, Protein Assay) and was calculated per $\mathrm{cm}$ of bowel length. Histological sections were prepared from the jejunal and ileal remnants. Pieces of proximal jejunum and terminal ileum near the ileo-cecal junction were placed in $5 \%$ phosphate-buffered formalin, washed with absolute alcohol, and embedded in paraffin, cut to 5 ( $\mathrm{m}$ thickness, and stained with hematoxylin-eosin. Fifteen of longest villi and crypts were selected for the microscopic analysis, using a $10 \times 4$ magnifying lens.

\section{Enterocyte proliferation and apoptosis}

Crypt cell proliferation was assessed using a biotinylated monoclonal anti-BrdU antibody system provided in a kit form (Zymed Laboratories, Inc, San Francisco, CA). An index of proliferation was determined as the ratio of crypt cells staining positively for BrdU per 10 crypts. Additional $5 \mu \mathrm{m}$ thick sections were prepared to establish the degree of enterocyte apoptosis. Immunohistochemistry for Caspase-3 (Caspase-3 cleaved concentrated polyclonal antibody; dilution 1:100; Biocare Medical, Walnut Creek, CA) was performed for identification of apoptotic cells using a combination of streptovidin-biotin-peroxidase method and microwave antigen retrieval on formalinfixed, paraffin-embedded tissues according to the manufacturers' protocols. For each group, the number of stained cells was counted in at least ten villi. The apoptotic index (AI) was defined as the number of apoptotic cells per ten villi. All measurements were performed by a qualified pathologist blinded as to the source of intestinal tissue.

\section{Expression of bax and bcl-2 genes (real-time PCR)}

Expression of Bax and Bcl-2 levels was determined by quantitative real-time PCR (7500 Real-Time PCR System, Applied Biosystems, USA) on cDNA samples using Cyber Green Master Mix (ROVALAB, Germany) with the exception of template and primers. Primers for Rattus norvegicus Bax and Bcl-2 were synthesized by Syntezza Bioscience ltd. Israel, and $18 \mathrm{~s}$ rRNA Control kit from Eurogentec, EGT Group.

\section{Western blotting}

Tissue from jejunum and ileum was homogenized in RIPA lysis buffer containing $50 \mathrm{mM}$ Tris- $\mathrm{HCl}$ (pH 7.4), $150 \mathrm{mM}$ $\mathrm{NaCl}, 1 \% \mathrm{NP}-40,2 \mathrm{mM}$ EDTA, supplemented with a cocktail of protease and phosphatase inhibitors. Protein concentrations were determined by Bradford reagent according to the manufacturer's instructions. Samples containing equal amounts of total protein $(30 \mu \mathrm{g})$ were resolved by SDS-PAGE under reducing conditions. After electrophoresis, proteins were transferred to a PVDF membrane and probed with various primary antibodies to anti-Bcl-2 antibody (1:1000 dilution, sc-7382), anti-Bax antibody (1:200 dilution, sc-493), anti-phospho-ERK antibody (1:2500 dilution, sc-7383), anti- $\beta$-catenin antibody (1:1000 dilution, sc-7199) and anti-ERK2 antibody (1:1000 dilution, sc-56899). Horseradish peroxidase-conjugated secondary antibody was purchased from Jackson ImmunoResearch Laboratories Inc. (West Grove, PA) and an enhanced chemiluminescent substrate from Biological 
Industries (Kibbutz Beth HaEmek, Israel). The optical density of the specific protein bands was quantified by using a densitometer (Vilber Lourmat, Lion, France).

\section{Statistical analysis}

The data are expressed as the mean \pm SEM. A one-way ANOVA for comparison, followed by Tukey's test for pair-wise comparison was used for statistical analysis. Prism software was used (GraphPad Software, Inc., San Diego, CA) and statistical significance was defined as $P<0.05$.

\section{Results}

\section{Water, arginine and energy intake}

Total water intake was $15-18 \mathrm{ml} / \mathrm{rat} /$ day. There was no significant difference in fluid intake between all experimental groups $(15 \mathrm{ml} / \mathrm{rat} /$ day in control animals and $18 \mathrm{ml} /$ rat/day in MTX-groups). The amount of additional protein was $300 \mathrm{mg} / \mathrm{rat} / \mathrm{a}$ day and additional calorie intake was $1.2 \mathrm{kcal} / \mathrm{rat} /$ day.

\section{Body weight changes}

MTX (Group C) rats demonstrated a significant decrease in final body weight $(100 \pm 2.6$ vs $106 \pm 0.4 \%$ initial weight, $\mathrm{p}<0.05)$ compared to control animals (Group A). Although treatment with oral arginine resulted in a trend toward increase in final body weight in both sham (Group B) and MTX (Group D) animals, this trend did not achieve statistical significance.

\section{Intestinal mucosal parameters}

Oral arginine administration in control animals (Group B) resulted in a mild decrease in bowel weight and mucosal weight in jejunum and ileum, as well as mucosal DNA content $(33 \%, \mathrm{p}<0.05)$ in jejunum compared to control animals (Table 1). MTX-induced intestinal damage (Group C) was associated with a significant decrease in bowel weight in jejunum $(26 \%, \mathrm{p}<0.05)$ and ileum $(20 \%$, $\mathrm{p}<0.05$ ), mucosal weight in jejunum (two-fold decrease, $\mathrm{p}<0.05$ ) and ileum (two-fold decrease 25\%, $\mathrm{p}<0.05$ ), mucosal DNA in jejunum and ileum (two-fold decrease, $\mathrm{p}<0.05)$, and mucosal protein in jejunum $(38 \%, \mathrm{p}<0.05)$ and ileum $(41 \%, \mathrm{p}<0.05)$ compared to control animals (Group A). Following dietary L-arginine administration (Group D), MTX-rats demonstrated a significant increase in bowel weight in jejunum $(12 \%, \mathrm{p}<0.05)$, bowel $(24 \%$, $\mathrm{p}<0.05)$ and mucosal $(30 \%, \mathrm{p}<0.05)$ weight in ileum, ileal mucosal DNA (two-fold increase, $\mathrm{p}<0.05$ ) and

Table 1 Intestinal mucosal parameters

\begin{tabular}{|c|c|c|c|c|}
\hline & CONTR & CONTR-ARG & MTX & MTX-ARG \\
\hline \multicolumn{5}{|l|}{ Bowel weight } \\
\hline \multicolumn{5}{|c|}{ (mg/cm/100 mg body weight) } \\
\hline Jejunum & $23 \pm 1$ & $21 \pm 1$ & $17 \pm 0.3 *$ & $19 \pm 1 *+$ \\
\hline Ileum & $21 \pm 1$ & $19 \pm 1$ & $17 \pm 1 *$ & $21 \pm 1 *+$ \\
\hline \multicolumn{5}{|c|}{ Mucosal weight } \\
\hline \multicolumn{5}{|c|}{ (mg/cm/100 mg body weight) } \\
\hline Jejunum & $9.4 \pm 0.5$ & $7.6 \pm 0.5 *$ & $5.1 \pm 0.6 *$ & $6.2 \pm 0.6$ \\
\hline Ileum & $9.1 \pm 0.5$ & $6.7 \pm 0.5 *$ & $4.7 \pm 0.5 *$ & $6.1 \pm 0.6 *+$ \\
\hline \multicolumn{5}{|l|}{ Mucosal DNA } \\
\hline \multicolumn{5}{|c|}{ ( $\mu \mathrm{g} / \mathrm{cm} / 100$ mg body weight) } \\
\hline Jejunum & $45 \pm 7$ & $30 \pm 4 *$ & $22 \pm 5 *$ & $25 \pm 3 *$ \\
\hline Ileum & $47 \pm 6$ & $52 \pm 4$ & $19 \pm 4 *$ & $38 \pm 9+$ \\
\hline \multicolumn{5}{|c|}{ Mucosal protein } \\
\hline \multicolumn{5}{|c|}{ ( $\mu \mathrm{g} / \mathrm{cm} / 100 \mathrm{mg}$ body weight) } \\
\hline Jejunum & $94 \pm 21$ & $60 \pm 11$ & $58 \pm 10 *$ & $58 \pm 5 *$ \\
\hline Ileum & $54 \pm 10$ & $44 \pm 8$ & $32 \pm 5 *$ & $51 \pm 8+$ \\
\hline \multicolumn{5}{|c|}{ Villus height ( $\mu \mathrm{m})$} \\
\hline Jejunum & $434 \pm 29$ & $345 \pm 56$ & $314 \pm 33 *$ & $413 \pm 18+$ \\
\hline Ileum & $371 \pm 26$ & $287 \pm 19 *$ & $217 \pm 52 *$ & $300 \pm 23 * \dagger$ \\
\hline \multicolumn{5}{|c|}{ Crypt depth $(\mu \mathrm{m})$} \\
\hline Jejunum & $183 \pm 17$ & $131 \pm 8 *$ & $112 \pm 4^{*}$ & $126 \pm 11$ \\
\hline Ileum & $161 \pm 16$ & $120 \pm 8$ * & $101 \pm 15^{*}$ & $131 \pm 10 *+$ \\
\hline
\end{tabular}

CONTR- control, MTX-methotrexate, ARG-arginine

* $\mathrm{P}<0.05$ All groups vs CONTR rats, $+\mathrm{P}<0.05$ MTX-ARG vs MTX rats. 
protein $(59 \%, \mathrm{p}<0.05)$ compared to MTX-untreated animals (Group C).

\section{Microscopic bowel appearance}

MTX rats showed severe villous atrophy, epithelial flattening, extensive crypt loss and signs of crypt remodeling, which was accompanied by marked cellularity and an increased number of blood vessels in the stroma (Figure 1A). The proliferative zone in MTX-rats moved progressively upwards in the crypts toward the crypt-villus junction (Figure 1B). At the same time, the proliferative zone of MTX-ARG rat was only mildly affected, showing a slight shift upwards within the crypts. Although the mucosa was still severely damaged, MTXARG rats showed the presence of newly formed crypts and regeneration.

Villus height and crypt depth significantly decreased in jejunum ( $28 \%$ and $39 \%$, correspondingly, $\mathrm{p}<0.05)$ and ileum $(42 \%$ and $37 \%$, correspondingly, $\mathrm{p}<0.05)$ in MTXrats compared to control animals (Table 1). Dietary L-arginine exerted different effects on the microscopic intestinal appearance in control and MTX animals. In control rats, oral arginine (Group B) resulted in a mild but significant decrease in villus height and crypt depth in jejunum and ileum compared to control animals (Group A). In MTX rats, dietary L-arginine (Group D) attenuated the negative effect of methotrexate on mucosal architecture. MTX-ARG rats showed greater villus height in jejunum $(32 \%, \mathrm{p}<0.05)$ and ileum $(38 \%$ increase, $\mathrm{p}<0.05)$, and crypt depth in ileum $(30 \%$ increase, $\mathrm{p}<0.05$ ) compared to MTX-animals (Group C).

\section{Cellular proliferation and apoptosis}

CONTR-ARG rats showed a trend toward a decrease in cell proliferation; however, this trend was not statistically significant (Figure 1). MTX intestinal damage (Group C) resulted in a significant decrease in enterocyte proliferation rates in jejunum $(128 \pm 12$ vs $197 \pm$ 14 BrdU positive cells/10crypts, $\mathrm{p}<0.05)$ and ileum $(133 \pm 21$ vs $210 \pm 22 \mathrm{BrdU}$ positive cells/10crypts, $\mathrm{p}<$ 0.05) when compared to control animals (Group A). Although treatment with dietary arginine of MTX-animals (Group D) resulted in a 10\% increase in cell proliferation rates in jejunum and ileum, this change was not statistically significant.

The frequency of apoptotic cells was increased in the animals following MTX-induced damage in jejunum $(1.8 \pm 0.2$ vs $0.8 \pm 0.37$ apoptotic cells $/ 1-$ villi, $\mathrm{p}<0.05)$ and ileum ( $1.5 \pm 0.3$ vs $0.6 \pm 0.13$ apoptotic cells/1- villi, $\mathrm{p}<0.05$ ) compared to control rats (Figure 1). Treatment with dietary arginine of MTX-animals (Group D) resulted in a significant two-fold decrease in cell apoptosis in both jejunum and ileum $(\mathrm{p}<0.05)$ compared to MTX-nontreated animals (Group C).

\section{Expression of apoptosis related genes}

CONTR-ARG (Group B) rats showed a small but significant increase in bax mRNA (pro-apoptotic factor) expression in jejunum (33\%) and ileum (53\%) compared to control animals (Figure 2). MTX rats (Group C) demonstrated a two-fold increase in bax mRNA expression in jejunum and ileum $(\mathrm{p}<0.05)$ as well as a two-fold decrease in bcl-2 gene (anti-apoptotic protein) expression ( $\mathrm{p}<0.05)$ in jejunum compared to control animals (Group A). Treatment with arginine resulted in a significant decrease in bax mRNA expression in jejunum $(38 \%, \mathrm{p}<0.05)$ and ileum $(41 \%, \mathrm{p}<0.05)$ and a concomitant decrease in bcl-2 gene expression in ileum $(44 \%, \mathrm{p}<0.05)$ compared to MTX animals (Figure 3).

\section{Western blotting}

Although western blot analysis of proliferation and apoptosis markers has demonstrated a similar tendency both in jejunum and ileum, more representative changes were observed in the terminal ileum. Western blot analysis (Figure 4) illustrated a significant decrease in bcl-2 protein levels as well as a significant increase in bax protein in MTX rats compared to control animals. These findings correlate with augmented cell apoptosis in MTX-animals compared to control rats. Decreased cell proliferation in this group coincided with decreased $\beta$-catenin levels. Treatment with arginine resulted in a significant increase in bcl-2 protein levels as well as a significant decrease in bax protein levels without changes in $\mathrm{p}$-ERK and $\beta$-catenin levels compared to MTX rats. These qualitative and quantitative changes are in agreement with the mRNA expression data and with decreased apoptosis and unchanged proliferation in ileum following ARG administration.

\section{Discussion}

In the last two decades, arginine has attracted major interest since it has been identified as the natural substrate of nitric oxide, and is now recognized to play a major role in many regulation processes. Nitric oxide is a multifunctional intercellular messenger molecule that plays an important role in a variety of physiological processes. Nitric oxide is synthesized from L-arginine by the inducible nitric oxide synthase (iNOS). Arginine and nitric oxide are critical to the normal physiology of the gastrointestinal tract and maintain the mucosal integrity of the intestine in various intestinal disorders. Arginine stimulates intestinal cell migration and intestinal protein synthesis through a focal adhesion kinase dependent mechanism in vitro [13]. Arginine supplementation enhances intestinal growth and development in weanling piglets [14]. Dietary supplementation with arginine stimulates small intestinal mucosal recovery following experimental radiation enteritis [15] and accelerates ulcer 


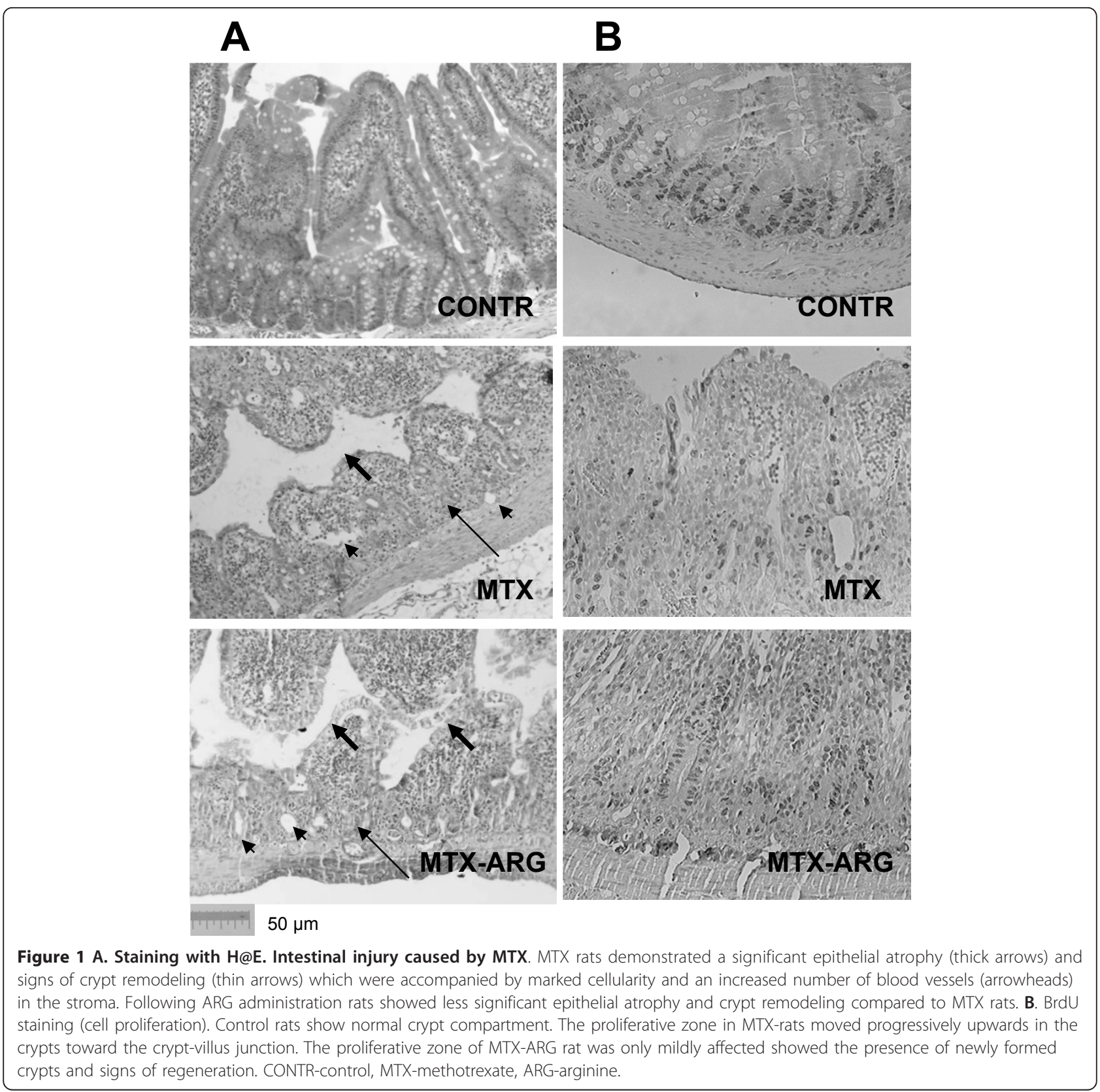

healing in experimental ulcerative ileitis [16]. In a recent study, we have shown that oral arginine decreases intestinal injury caused by lipopolysacharide endotoxemia in a rat [9]. In another study, we have demonstrated that oral arginine administration improves mucosal recovery following intestinal ischemia-reperfusion injury in a rat [10]. The mechanisms of these positive effects are still unclear; however, a stimulating effect of appropriate amounts of $\mathrm{NO}$ on enterocyte proliferation and a suppressive effect on enterocyte death via apoptosis may be considered as one of them.
The role of arginine in prevention of chemotherapyinduced intestinal damage is unclear. Hämäläinen Met al have shown recently that chemotherapy inhibites iNOS expression, and subsequent NO production, in a dosedependent manner at therapeutically achievable drug concentrations in a human colon epithelial cell line [17]. In a recent experiment, Gulgun et al. have demonstrated that proanthocyanidin, arginine and glutamine supplementation had a positive effect in the protection of the small intestine from methotrexate-induced injury [18]. The mechanisms of this effect were not investigated. In a 


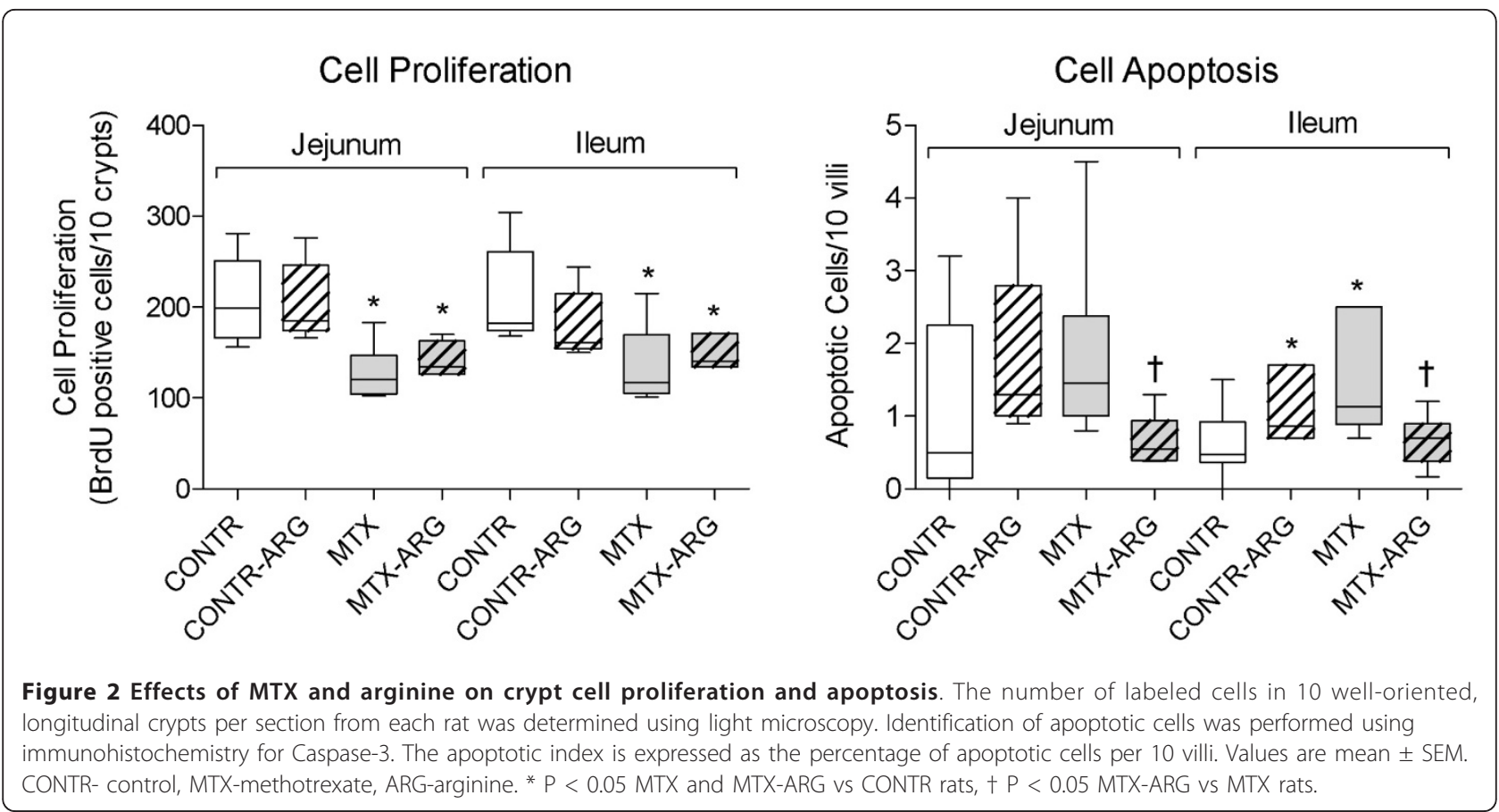

recent clinical trial, Izaola et al. have shown that arginine and glutamine enhanced formula decreases the rate of radiotherapy-induced oral mucositis in patients with head and neck cancer [19].

Methotrexate is the most commonly used anti-metabolite agent in clinical oncology practice. Since ARG maintains the mucosal integrity of the intestine in various intestinal disorders, we hypothesized in the present study that this amino acid could prevent intestinal mucosal injury or/and improve intestinal recovery following MTX-induced mucositis. Alterations in bowel and mucosal weights, mucosal DNA and protein content and histological appearance were measured. BrdU was used in our experiment to determine an index of crypt

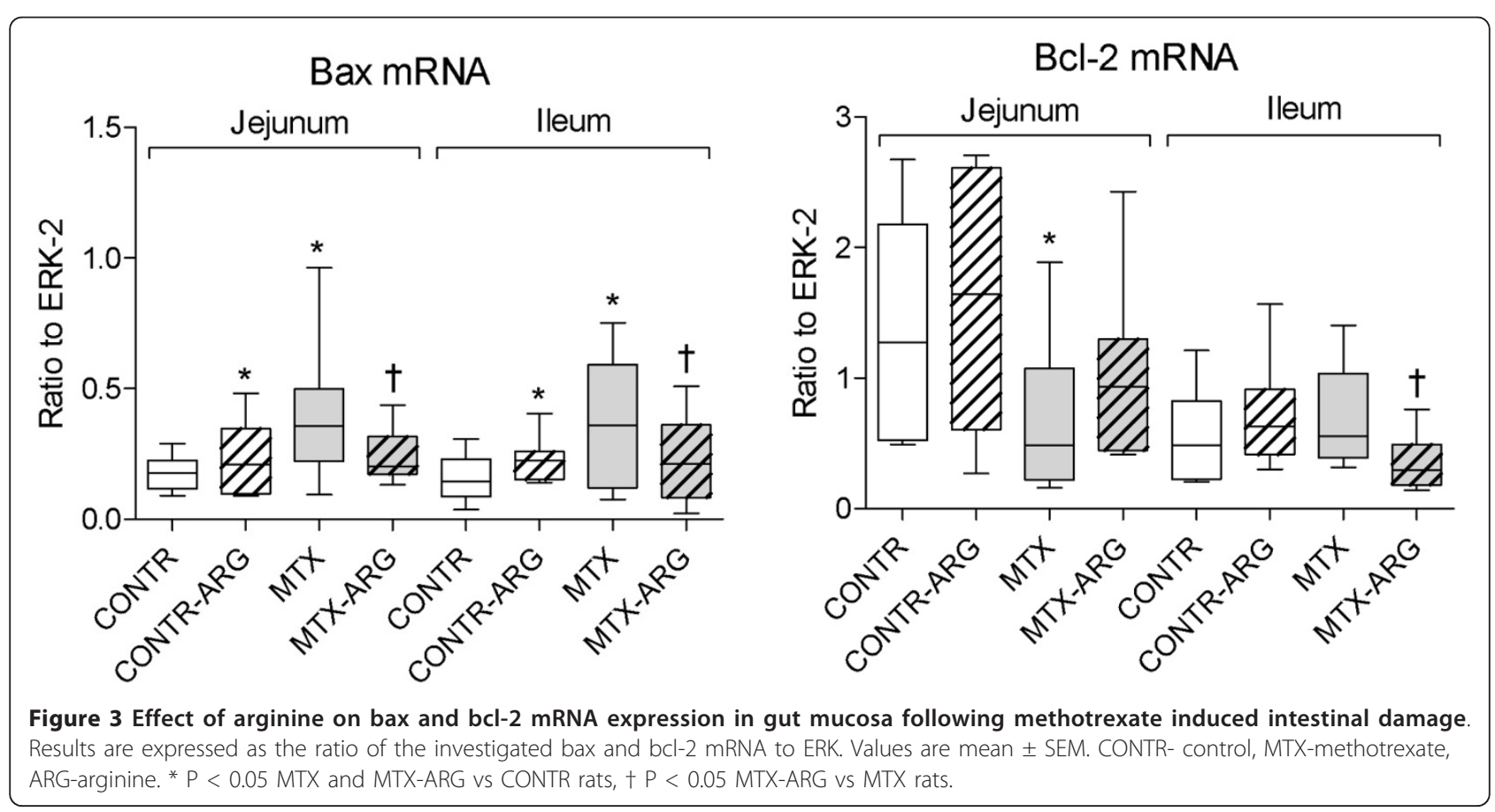




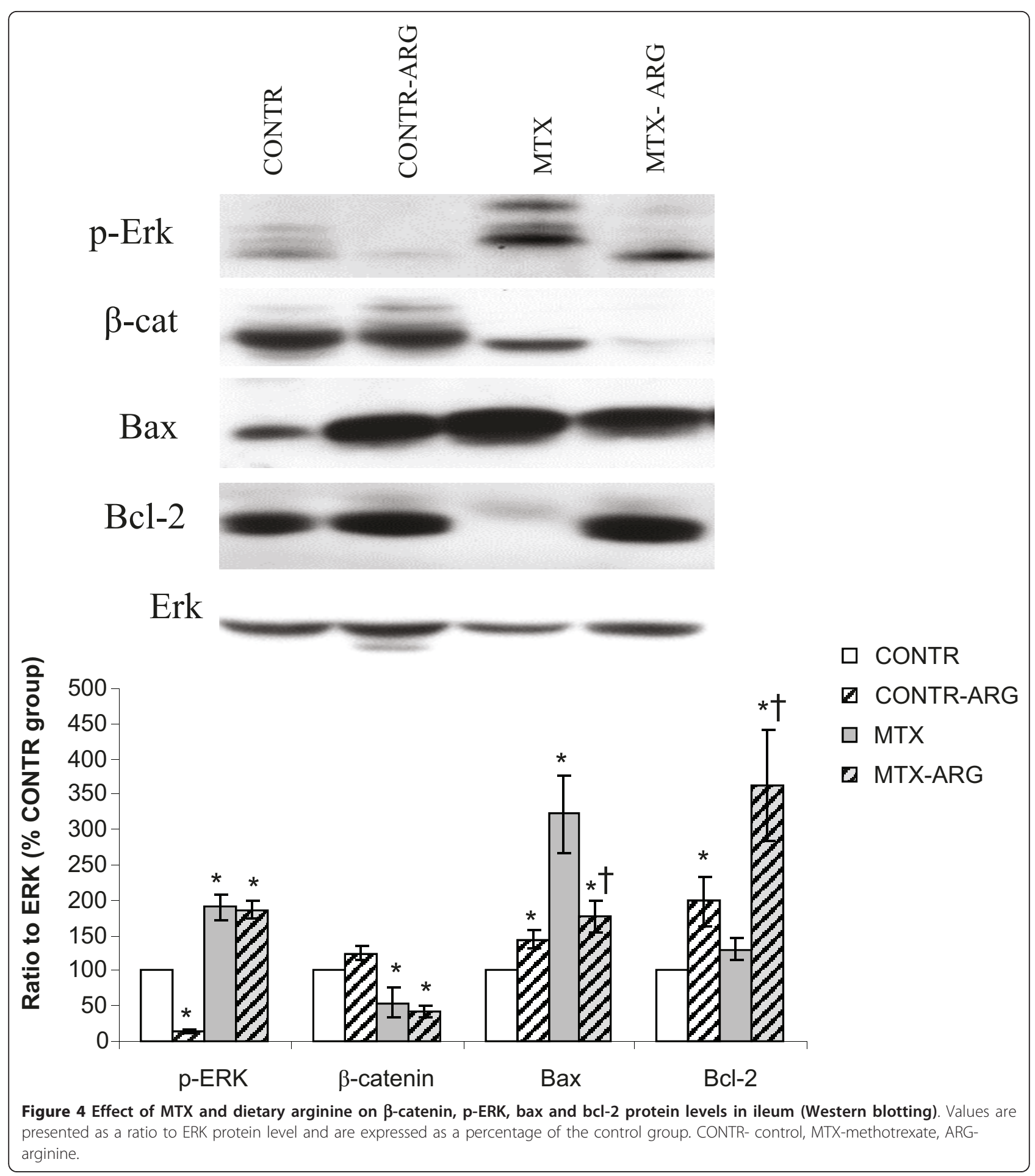

cell proliferation. Immunohistochemistry for caspase-3 was used to characterize enterocyte apoptosis. We have demonstrated that a single dose of MTX caused a severe mucosal injury in the small bowel, indicated by severe villous atrophy, epithelial flattening, intensive crypt loss and signs of crypt remodeling, which was accompanied by marked cellularity and an increased number of blood vessels in stroma. In addition, treatment with MTX resulted in significant mucosal hypoplasia. A decrease in bowel and mucosal weight, mucosal DNA and protein, and decrease in villus height support this conclusion. Parallel decreases in mucosal DNA and protein indicate 
that the smaller mucosal mass of MTX animals can be attributed to cellular hypoplasia. Histologically, villus height decreased in response to MTX administration, suggesting decreased absorptive surface area. Mucosal DNA content as well as the enterocyte proliferation index decreased significantly in both jejunum and ileum following MTX administration. MTX is an analog of folic acid and works by attaching to dehydrofolate reductase to inhibit DNA production. As a result crypt proliferation in the small bowel is inhibited. In addition, the proliferative zone in MTX-rats moved progressively upwards in the crypts toward the crypt-villus junction. The mechanism responsible for this effect is poorly understood. Verburg and coworkers have shown in MTX-treated rats that BrdU-positive cells are not restricted to the crypts but are also found in up to onethird of the length of the villi due to migration of the cells [20]. Our data suggest that MTX animals had lower $\beta$-catenin levels which fits with decreased cell proliferation. Extensive experimental evidence suggests that $\mathrm{Wnt} / \beta$-catenin signaling plays a central role in maintaining the intestinal stem-cell niche and in regulating differentiation of stem cells within the intestinal epithelium toward either enterocytes or one of three secretory cell lineages (Paneth, goblet, or enteroendocrine cells [21]. Cell loss in the small intestine MTX-induced mucositis is mainly regulated by programmed cell death. Our results show that the intrinsic pathway, with its regulation by the bcl-2 family of proteins, was altered by MTX consistent with changes in cell apoptosis: the mRNA levels of the pro-apoptotic gene bax increased, while those of the antiapoptotic bcl-2 gene decreased. With regard to the protein level, qualitative and quantitative changes were in agreement with mRNA expression. Bax protein levels were significantly up-regulated while bcl-2 protein levels were down regulated in MTXtreated rats compared to control animals. These changes correlate with the enhanced enterocyte apoptosis during MTX-induced mucositis.

Results of the present study show that dietary arginine protects the intestinal mucosa from damage caused by MTX. While MTX rats showed severe villous atrophy, epithelial flattening, extensive crypt loss and signs of crypt remodeling, marked cellularity and an increased number of blood vessels in stroma, arginine-treated rats showed more preserved architecture as well as the presence of newly formed crypts and regeneration. While the proliferative zone in MTX-rats moved progressively upwards in the crypts toward the crypt-villus junction, the proliferative zone of MTX-ARG rats was only mildly affected, showing a slight shift upwards within the crypts. In addition, exposure to oral arginine significantly enhanced intestinal recovery following MTXinduced damage. This is evident from the significant increase in bowel and mucosal, increased DNA and protein content in ileum. Increased mucosal weight without changes in mucosal surface area may suggest that mucosal hyperplasia rather than bowel enlargement or intestinal muscle hypertrophy is responsible for the increased intestinal mass. Increase in mucosal DNA and protein along with hypertrophy of the individual cells which we have demonstrated morphometrically is characteristic of tissues undergoing increased cell proliferation or repair. Histologically, marked increases in villus height in both jejunum and ileum suggest increased absorptive surface area and closely correlate with increased cell mass. The present data suggest that arginine did not change significantly mucosal proliferation in functioning intestine, but decreased significantly cell apoptosis rate, which may represent the main mechanism that maintains mucosal structure following MTX-induced damage. Our results show that the intrinsic pathway, with its regulation by the bcl-2 family of proteins, was altered by arginine in accordance with changes in cell apoptosis: the mRNA and protein levels of the pro-apoptotic bax decreased, while those of the antiapoptotic bcl-2 protein levels increased. Correspondingly, bax/bcl-2 ratio decreased in MTX-ARG rats compared to MTX animals, suggesting increased enterocyte survival. Further investigation is needed to define the regulation of this special apoptotic state with respect to the Fas/Fasl-mediated extrinsic pathway.

The mechanism of the positive effects of arginine is unclear. In non-operated, non-stressed animal, total food intake is $20-25 \mathrm{~g} / \mathrm{rat} /$ day, total protein intake is about $6 \mathrm{~g} / \mathrm{rat} / \mathrm{day}$, and total energy intake is $100 \mathrm{kcal} /$ $\mathrm{rat} /$ day [22]. We do not believe that an additional 300 $\mathrm{mg} / \mathrm{rat} /$ day of protein (vs $6 \mathrm{~g}$ of total protein) as well as additional energy of $1.2 \mathrm{kcal} / \mathrm{rat}$ (vs total $100 \mathrm{kcal} / \mathrm{rat} /$ day) may have influenced the results. The limitation of the current experiment is a lack of isonitrogenous MTX group. Therefore, this study is not able to prove that arginine supply limits intestinal damage. It was previously reported that other amino acids (like glutamine, glycine or histidine) have protective effects on intestinal mucosa during chemotherapy or inflammatory conditions. An additional MTX-isonitrogenous amino acid group will be added in future study to determine whether other amino acids have similar effects.

\section{Conclusions}

In a rat model of methotrexate-induced mucositis, administration of dietary arginine prevents intestinal damage, decreases cell death via apoptosis and accelerates intestinal recovery. These preliminary observations suggest that oral arginine may have clinical value in preventing or reducing the severity of chemotherapyinduced mucositis. 


\section{Acknowledgements}

This work was supported by a research grant from Israeli Ministry of Health No $3 / 6164$ from 01/06/10

\section{Author details}

${ }^{1}$ The Bruce Rappaport Faculty of Medicine, Technion-Israel Institute of Technology, Laboratory of intestinal adaptation and recovery, Haifa, Israel. ${ }^{2}$ Department of Pediatric Surgery, Bnai Zion Medical Center, Haifa, Israel. ${ }^{3}$ Department of Surgery, Bnai Zion Medical Center, Haifa, Israel. ${ }^{4}$ Department of Pathology, Bnai Zion Medical Center, Haifa, Israel. ${ }^{5}$ Section of Pediatric Surgery C.S. Mott Children's Hospital and University of Michigan Medical School, Ann Arbor, MI, USA.

\section{Authors' contributions}

TK was responsible for conception and participation in design, experimental work and collection of data, analysis and interpretation of results, drifting and substantial editing the manuscript. YP was responsible for experimental work and collection of data, analysis and interpretation of results. JM was responsible conception and participation in design, analysis and interpretation of results. JB was responsible for experimental work and collection of data, analysis and interpretation of results. AGC participated actively in the conceptualization of the paper, analyses plan and provided critical reviews on the manuscripts. IS participated conceptualization, interpretation of the findings, drafting and editing of the manuscript. All authors read and approved the final manuscript.

\section{Competing interests}

The authors declare that they have no competing interests.

Received: 22 September 2011 Accepted: 30 April 2012

Published: 30 April 2012

\section{References}

1. Pico JL, Avila-Garavito A, Naccache P: Mucositis: its occurrence, consequences, and treatment in the oncology setting. Oncologist 1998, 3:446-451

2. Sonis ST: Complications of cancer and their treatment: oral complications. In Cancer Medicine.. 3 edition. Edited by: Holland JF, Frei E, Bast RC. Philadelphia: Lea and Febiger; 1993:2381-2388.

3. Logan RM, Stringer AM, Bowen JM, Yeoh AS, Gibson RJ, Sonis ST, Keefe DM: The role of pro-inflammatory cytokines in cancer treatment-induced alimentary tract mucositis: pathobiology, animal models and cytotoxic drugs. Cancer Treat Rev 2007, 33:448-460.

4. Kirk SJ, Barbul A: Role of arginine in trauma, sepsis and immunity. JPEN 1990, 14(Suppl 5):226-229.

5. Anggard E: Nitric oxide: mediator, murderer, and medicine. Lancet 1994 14:1199-1206.

6. Popovic PJ, Zeh HJ, Ochoa JB: Arginine and immunity. J Nutr 2007 137:1681-1686

7. Gurbuz AT, Kunzelman J, Ratzer EE: Supplemental dietary arginine accelerates intestinal mucosal regeneration and enhances bacterial clearance following radiation enteritis in rats. J Surg Res 1998, 74:149-154.

8. Sukumar P, Loo A, Magur E: Dietary supplementation of nucleotides and arginine promotes healing of small bowel ulcers in experimental ulcerative ileitis. Dig Dis Sci 1997, 42:1530-1536.

9. Sukhotnik I, Mogilner J, Krausz MM, Lurie M, Shiloni E: Oral arginine reduces gut mucosal injury caused by lipopolysaccharide endotoxemia in a rat. J Surg Res 2004, 122:256-262.

10. Sukhotnik I, Helou H, Mogilner J, Lurie M, Bernsteyn A, Coran AG, Shiloni E: Oral arginine improves intestinal recovery following ischemiareperfusion injury in rat. Pediatr Surg Int 2005, 21:191-196.

11. Drover JW, Dhaliwal R, Weitzel L, Wischmeyer PE, Ochoa JB, Heyland DK Perioperative use of arginine-supplemented diets: a systematic review of the evidence. J Am Coll Surg 2011, 212:385-399.

12. Chomczynski $P$ : A reagent for the single-step simultaneous isolation of RNA, DNA and proteins from cell and tissue samples. BioTechniques 1993, 15:532-533.

13. Rhoads JM, Chen W, Gookin J, Wu GY, Fu Q, Blikslager AT, Rippe RA Argenzio RA, Cance WG, Weaver EM, Romer LH: Arginine stimulates intestinal cell migration through a focal adhesion kinase dependent mechanism. Gut 2004, 53:514-522.
14. Yao K, Guan S, Li T, Huang R, Wu G, Ruan Z, Yin Y: Dietary L-arginine supplementation enhances intestinal development and expression of vascular endothelial growth factor in weanling piglets. Br J Nutr 2011, 105:703-709

15. Gurbuz AT, Kunzelman J, Ratzer EE: Supplemental dietary arginine accelerates intestinal mucosal regeneration and enhances bacterial clearance following radiation enteritis in rats. J Surg Res 1998, 74:149-154.

16. Sukumar P, Loo A, Magur E: Dietary supplementation of nucleotides and arginine promotes healing of small bowel ulcers in experimental ulcerative ileitis. Dig Dis Sci 1997, 42:1530-1536.

17. Hämäläinen $M$, Lahti $A$, Moilanen E: Calcineurin inhibitors, cyclosporin A and tacrolimus inhibit expression of inducible nitric oxide synthase in colon epithelial and macrophage cell lines. Eur J Pharmacol 2002, 448:239-244.

18. Gulgun M, Karaoglu A, Kesik V, Kurt B, Erdem O, Tok D, Kismet E, Koseoglu V, Ozcan O: Effect of proanthocyanidin, arginine and glutamine supplementation on methotrexate-induced gastrointestinal toxicity in rats. Methods Find Exp Clin Pharmacol 2010, 32:657-661.

19. Izaola O, de Luis DA, Cuellar L, Terroba MC, Ventosa M, Martin T, Aller R: Influence of an immuno-enhanced formula in postsurgical ambulatory patients with head and neck cancer. Nutr Hosp 2010, 25:793-796.

20. Verburg M, Renes IB, Meijer HP, Taminiau JA, Büller HA, Einerhand AW: Selective sparing of goblet cells and Paneth cells in the intestine of methotrexate-treated rats. Am J Physiol Gastrointest Liver Physiol 2000, 279: G1037-G1047.

21. Haegebarth A, Clevers H: Wnt signaling, Lgr5, and stem cells in the intestine. Am J Pathol 2009, 174:15-21.

22. Sukhotnik I, Gork AS, Chen M, Drongowski RA, Coran AG, Harmon CM: Effect of a high fat diet on lipid absorption and fatty acid transport in a rat model of short bowel syndrome. Pediatr Surg Int 2003, 19:385-390.

\section{Pre-publication history}

The pre-publication history for this paper can be accessed here: http://www.biomedcentral.com/1471-230X/12/41/prepub

doi:10.1186/1471-230X-12-41

Cite this article as: Koppelmann et al:: Dietary L-arginine

supplementation reduces Methotrexate-induced intestinal mucosa injury in rat. BMC Gastroenterology 2012 12:41

\section{Submit your next manuscript to BioMed Central and take full advantage of:}

- Convenient online submission

- Thorough peer review

- No space constraints or color figure charges

- Immediate publication on acceptance

- Inclusion in PubMed, CAS, Scopus and Google Scholar

- Research which is freely available for redistribution
C Biomed Central 